\title{
Frequency of alcohol use and obesity in community medicine patients
}

\author{
James E Rohrer*1, Barbara M Rohland ${ }^{2}$, Anne Denison ${ }^{1}$ and Anthony Way ${ }^{3}$
}

Address: ${ }^{1}$ Health Services Research, Department of Family and Community Medicine, Texas Tech University Health Sciences Center, Amarillo, Texas, United States, ${ }^{2}$ Department of Psychiatry, Texas Tech University Health Sciences Center, Amarillo, Texas, USA and ${ }^{3}$ Preventive Medicine, Department of Family and Community Medicine, Texas Tech University Health Sciences Center, Lubbock, Texas, USA

Email: James E Rohrer* - james.rohrer@ttuhsc.edu; Barbara M Rohland - barbara.rohland@ttuhsc.edu;

Anne Denison - anne.denison@ttuhsc.edu; Anthony Way - anthony.way@ttuhsc.edu

* Corresponding author

Published: 22 April 2005

BMC Family Practice 2005, 6:17 doi:10.1186/1471-2296-6-17

This article is available from: http://www.biomedcentral.com/I47/-2296/6/17

(c) 2005 Rohrer et al; licensee BioMed Central Ltd.

This is an Open Access article distributed under the terms of the Creative Commons Attribution License (http://creativecommons.org/licenses/by/2.0), which permits unrestricted use, distribution, and reproduction in any medium, provided the original work is properly cited.
Received: 03 January 2005

Accepted: 22 April 2005

\begin{abstract}
Background: Obesity is an important public health problem. However, the effects of alcohol use on the risk for obesity have not been thoroughly explored. This study focuses on how frequency of alcohol use is related to the risk of obesity in a community medicine clinic population.

Methods: This study used a cross-sectional survey to test the hypothesis that obesity (BMI > 30) is associated with alcohol use. The convenience sample was drawn from three clinics that primarily serve low-income populations. Independent variables included frequency of alcohol use, frequency of binge drinking, demographic characteristics, health behaviors and health status.

Results: In comparison to non-drinkers, people who consumed alcohol 3 or more days per month had lower odds of being obese (Adjusted Odds Ratio $=.49, \mathrm{p}<.04$ ). As expected, there was a significant association between watching eight or more hours of television per day and obesity $(A O R=2.34, p<.01)$.

Conclusion: More frequent drinking and less television time are independently associated with reduced odds of obesity in this sample of community medicine patients. Additional research is needed to isolate casual mechanisms.
\end{abstract}

\section{Background}

Overweight and obesity are subjects of much public health scrutiny and concern. Obesity is significantly correlated with many chronic diseases, including diabetes, cardiovascular disease, some cancers, and gallbladder disease. The Centers for Disease Control and Prevention (CDC) estimates that in 2003 healthcare expenditures attributable to obesity reached $\$ 75$ billion [1].

Weight control involves a complex interaction of physical, genetic, psycho-social and environmental factors.
Addressing the problem requires a solid understanding of the risk factors and how they can be influenced. Epidemiologists have studied the health consequences of obesity [2-4], and several studies have explored the risk factors for obesity [5-13]. The health behaviors that determine obesity, such as eating too much and exercising too little, are related to other health behaviors such as cigarette smoking and alcohol consumption. However, no consensus has emerged as to casual connections among these behaviors. 
Investigators from the National Institutes of Health analyzed the 2001 National Health Interview Survey to estimate the prevalence of multiple behavioral risk factors for chronic diseases [14]. These investigators found that 17 percent of adults had three or more of the following risk factors: cigarette smoking, risky drinking of alcoholic beverages, physical inactivity, and overweight. Less than ten percent of Americans had zero risk factors. About 73 percent had only one or two risk factors, proving that unhealthy behaviors do not always co-occur. We note that smoking illustrates the complexity of these relationships since it is a risk factor for most chronic diseases but is inversely related to obesity.

The purpose of this study was to investigate the importance of alcohol consumption in predicting self-reported obesity in a sample of primary care patients visiting community medicine clinics. The analysis adjusts for the impact of other health behaviors.

\section{Methods}

This study used a cross-sectional survey to test the hypothesis that obesity (BMI > 30) is associated with alcohol consumption in a community medicine population. This study was approved by the Institutional Review Board of Texas Tech Health Sciences Center (Amarillo). The convenience sample was drawn from three clinics that serve low-income populations. Participation was voluntary. Pregnant women and persons under age 18 were excluded from participation. Of 1471 surveys distributed to patients and accompanying adult family members, completed forms were received from 793 (54\%). Return rates varied by clinic. Height and weight responses were complete for 747 subjects.

Clinic 1 is a university-based family medicine clinic providing a full range of primary care services to cross-generational clients. It is staffed by family medicine physicians and residents. Daily census was approximately 85 clients daily, of which, less than $5 \%$ were non-English speaking. Clinic personnel distributed 500 survey forms over an eight week period with an $80.8 \%$ return rate. Clinic 2 serves women and children, providing obstetrical, well care (including immunizations), and acute care services to a targeted high-risk, low socioeconomic sub-population. It is staffed by pediatric and OB-GYN physicians and residents. Approximately $30 \%$ of the clinic clients do not speak English. A total of 471 surveys were distributed over a period of 18 weeks with a return of $37.6 \%$. Both the large number of obstetrical patients (ineligible for survey) and percentage of non-English speaking clients contributed to the low return rate. Clinic 3 provides primary care services to a population of indigent adults meeting residential and income screening requirements. It is staffed by internal medicine physicians and residents. A total of 500 surveys were distributed in this clinic over a ten week period with a return of $42.6 \%$.

The dependent variable was BMI calculated from selfreported height and weight data. Of 793 completed surveys, a BMI could be calculated for 747 . The continuous BMI variable was collapsed into two classifications: NonObese (BMI <30) and Obese (BMI $\geq 30)$.

Alcohol use was measured by both frequency and intensity. Frequency of alcohol consumption was measured as days per month (grouped into none, 1-2 and 3 or more). Intensity of alcohol consumption as measured by frequency of bingeing (times per month when drank five or more drinks, grouped as none, 1-2 and 3 or more). Other independent variables included gender, age, race/ethnicity (non-Hispanic White, Hispanic, Black, other), marital status (married vs single), educational level (less than high school, high school, some college, college graduate), number of persons living in the home (just me, one additional person, two or more), number of places to walk (none, one place, two or more), worry about having enough food (yes vs no), frequent mental distress (less than 15 days per month versus 15 or more), hours spent watching TV daily (less than $3,3-7$, or 8 or more), number of cigarettes per day (none, 1-20, more than 20), days per week of impaired activities of daily living (none vs one or more), days per week of exercise (none, 1-3, 4 or more) and health confidence. Health confidence was measured by the respondent's confidence that he or she can take of her own health (strongly agree, agree, not sure, disagree, strongly disagree).

Initial bivariate analysis using Pearson $\chi^{2}$ was used to identify associations between obesity and the independent variables. Variables with $p$ values less than 0.1 in the bivariate tests were retained for inclusion in a multivariate logistic regression model. Some cases were dropped due to missing data, resulting in a final sample of 594 in the regression model.

\section{Results}

Of the 747 calculated BMI measurements, 515 (65\%) fell into the overweight and obese categories. This is very similar to the BRFSS 2002 overweight/obese percentage of $63 \%$ for the state of Texas as a whole. Approximately, $40 \%$ of the sample BMI measurements were equal or greater than 30 (obese range). About 70\% of respondents were non-drinkers and about $90 \%$ never binged.

In the univariate analyses, there was no statistically significant difference in obesity by gender, race/ethnicity, educational level, marital status or family size. Days per month of alcohol use was associated with obesity ( $\mathrm{p}=$ $.001)$, as was intensity $(\mathrm{p}=.01)$. Both bingers and daily 
Table I: Percent Obese by Socioeconomic Characteristics of Sample $(\mathbf{N}=\mathbf{7 4 7})$

\begin{tabular}{|c|c|c|c|c|}
\hline & $\begin{array}{c}\text { Overall } \\
\%(\#)\end{array}$ & $\begin{array}{c}\text { Not Obese } \\
\%\end{array}$ & $\begin{array}{c}\text { Obese } \\
\%\end{array}$ & $p$-value \\
\hline Gender\% & & & & 0.734 \\
\hline Male & $19.46(144)$ & 61.11 & 38.89 & \\
\hline Female & $80.45(596)$ & 59.56 & 40.44 & \\
\hline Age group\% & & & & 0.004 \\
\hline Under 35 & $36.44(270)$ & 66.67 & 33.33 & \\
\hline $35-45$ & $19.57(145)$ & 56.55 & 43.45 & \\
\hline $46-55$ & $18.89(140)$ & 48.57 & 51.43 & \\
\hline $56-65$ & $12.42(92)$ & 56.52 & 43.48 & \\
\hline Over 65 & $12.69(94)$ & 65.96 & 34.04 & \\
\hline Race/ethnicity\% & & & & 0.367 \\
\hline non-Hispanic White & $67.40(490)$ & 61.22 & 38.78 & \\
\hline Hispanic & $23.93(174)$ & 56.90 & 43.10 & \\
\hline Black & $7.29(53)$ & 50.94 & 49.06 & \\
\hline Other & $1.38(10)$ & 70.00 & 30.00 & \\
\hline Marital status\% & & & & 0.145 \\
\hline Married & $52.94(234)$ & 62.57 & 37.43 & \\
\hline Single & $47.46(140)$ & 57.30 & 42.70 & \\
\hline Educational status\% & & & & 0.148 \\
\hline$<$ high school degree & $8.67(35)$ & 54.69 & 45.31 & \\
\hline high school degree & $36.86(272)$ & 64.71 & 35.29 & \\
\hline Some college & $38.48(284)$ & 55.99 & 44.01 & \\
\hline college graduate & $15.99(118)$ & 61.86 & 38.14 & \\
\hline Number of persons living in the home\% & & & & 0.956 \\
\hline Just me & $16.21(119)$ & 60.50 & 39.50 & \\
\hline One additional person & $26.29(193)$ & 60.62 & 39.38 & \\
\hline Two or more & $57.49(422)$ & 59.48 & 40.52 & \\
\hline Number of places to walk\% & & & & 0.023 \\
\hline None & $29.91(210)$ & 52.38 & 47.62 & \\
\hline One place & $15.95(\mid 12)$ & 60.71 & 39.29 & \\
\hline Two or more & $54.13(380)$ & 63.95 & 36.05 & \\
\hline Worried about having enough food\% & & & & 0.033 \\
\hline Yes & $26.91(194)$ & 53.09 & 46.91 & \\
\hline No & $73.09(527)$ & 61.86 & 38.14 & \\
\hline
\end{tabular}

drinkers were less likely to be obese. Age was significantly associated with obesity, as was number of places to walk, worry about having enough food, health confidence, frequent mental distress, hours watching TV, not smoking cigarettes, frequent mental distress, days with impaired ADLs, and days per week of exercise (see Tables 1 and 2).

In the multivariate analysis, having places to walk, days with impaired ADLs, and being worried about food, and days of exercise per week were not found to be independently related to obesity (Table 3). Obesity was inversely related to cigarette smoking. Specifically, in comparison to non-smokers, persons who smoked 1-20 cigarettes per day had significantly lower adjusted odds of being obese $(\mathrm{AOR}=.56)$ and persons who smoked more than 20 cigarettes per day did as well $(\mathrm{AOR}=.33)$.
In comparison to non-drinkers, people who consumed alcohol 3 or more days per month had lower odds of being obese $(\mathrm{AOR}=.49, \mathrm{p}=.037)$. Binge drinking was not significantly related to obesity. However, we note that only 43 respondents binged three or more times per month. Therefore, power may not have been adequate to test this hypothesis.

As expected, there was a strong association between watching eight or more hours of television per day and obesity (AOR $=2.34, \mathrm{p}<.01)$.

Persons who were not sure about the statement "I have usually been able to take care of my own health without the help of a doctor or a nurse" had increased odds of being obese (adjusted odds ratio $=2.01, \mathrm{p}=0.034$ ). There 
Table 2: Percent Obese by Health and Behavioral Characteristics of Sample $(\mathbf{N}=747)$

\begin{tabular}{|c|c|c|c|c|}
\hline & $\begin{array}{c}\text { Overall } \\
\%(\#)\end{array}$ & $\begin{array}{c}\text { Not Obese } \\
\%\end{array}$ & $\begin{array}{c}\text { Obese } \\
\%\end{array}$ & $p$-value \\
\hline Usually can take care of own health\% & & & & 0.020 \\
\hline Strongly agree & $20.08(142)$ & 69.72 & 30.28 & \\
\hline Agree & $35.79(253)$ & 62.06 & 37.94 & \\
\hline Not sure & $13.30(94)$ & 53.19 & 46.81 & \\
\hline Disagree & $22.21(157)$ & 52.87 & 47.13 & \\
\hline Strongly disagree & $8.63(61)$ & 55.74 & 44.26 & \\
\hline Frequent mental distress $\%$ & & & & 0.001 \\
\hline Less than 15 days/month & $72.50(5 \mid 4)$ & 63.81 & 36.19 & \\
\hline 15 days or more & $27.50(195)$ & 50.26 & 49.74 & \\
\hline Days with impaired ADL\% & & & & 0.027 \\
\hline None & $58.92(4 \mid 6)$ & 63.46 & 36.54 & \\
\hline One or more & $41.08(290)$ & 55.17 & 44.83 & \\
\hline Hours spent watching TV daily\% & & & & 0.001 \\
\hline Less than 3 & $39.4 \mid(256)$ & 65.63 & 34.38 & \\
\hline 3 to 7 hours & $50.00(327)$ & 54.74 & 45.26 & \\
\hline 8 or more & $10.86(7 I)$ & 42.25 & 57.75 & \\
\hline Number of cigarettes per day\% & & & & 0.008 \\
\hline None & $71.72(535)$ & 56.26 & 43.74 & \\
\hline I to 20 & $20.11(150)$ & 68.67 & 31.33 & \\
\hline More than 20 & $8.18(6 I)$ & 68.85 & 31.15 & \\
\hline Drink days per month\% & & & & 0.001 \\
\hline None & $69.45(516)$ & 55.62 & 44.38 & \\
\hline I to 2 & $16.15(120)$ & 65.83 & 34.17 & \\
\hline 3 or more & $14.14(107)$ & 73.83 & 26.17 & \\
\hline 5+ Drinks/day per month \% & & & & 0.010 \\
\hline None & $86.35(639)$ & 58.22 & 41.78 & \\
\hline I to 2 & $7.85(58)$ & 62.07 & 37.93 & \\
\hline 3 or more & $5.81(43)$ & 81.40 & 18.60 & \\
\hline Days/Week Exercise\% & & & & 0.005 \\
\hline None & $31.65(226)$ & 57.96 & 42.04 & \\
\hline I to 3 & $45.10(322)$ & 54.04 & 45.96 & \\
\hline 4 or more & $23.25(166)$ & 69.28 & 30.72 & \\
\hline
\end{tabular}

was a higher degree of poor mental health as measured by frequent mental distress among obese respondents (AOR $=1.56, \mathrm{p}=0.043$ ).

\section{Discussion}

Recent epidemiological studies of alcohol use and health have measured alcohol use in a variety of ways. Some measured frequency of alcohol use while others measured intensity (drinks per occasion or total drinks) and some measure alcohol use both ways. Researchers also measured obesity in several different ways. These have included body mass index, waist circumference, and hip circumference.

The relationship between episodic heavy alcohol use and overall self-rated health was examined by Okosun et al [15]. Episodic heavy drinking was defined as consumption of 5 or more drinks at one occasion (for men) or 4 or more drinks (for women). This kind of bingeing was a sig- nificant risk factor for poor self-rated health. Okosun et al did not report any findings relating to total drinks per week or number of drinking episodes.

Paschall, Freisthler and Lipton, who studied alcohol use and depression among young adults created seven categories of alcohol use based on drinks per occasion rather than frequency of drinking [16]. They defined moderate drinking as no more than 1-2 drinks per occasion. Their analysis of data from the National Longitudinal Study of Adolescent Health showed that moderate drinkers were less likely to have depressive symptoms than either heavy drinkers or abstainers. Since depression and alcohol use both are related to obesity, this is an important finding.

Vadstrup et al studied waist circumference in a large population survey of Danish adults [10]. They measured alcohol use with total number of drinks per week but counted neither the number of drinking days nor the number of 
Table 3: Multiple logistic regression analysis* of obesity (BMI greater than or equal to 30 ) in community medicine patients $(\mathrm{N}=594)$

\begin{tabular}{|c|c|c|}
\hline & Odds Ratio (95\% C.I.) & p-value \\
\hline \multicolumn{3}{|c|}{ Days/Week Exercise } \\
\hline None & Reference & \\
\hline One to three & $1.22(0.8 \mathrm{I}-1.86)$ & $0.34 I$ \\
\hline Four or more & $0.61(0.37-1.01)$ & 0.054 \\
\hline \multicolumn{3}{|c|}{ Usually can take care of own health } \\
\hline Strongly Agree & Reference & \\
\hline Agree & $1.32(0.79-2.19)$ & 0.286 \\
\hline Not Sure & $2.01(1.05-3.82)$ & 0.034 \\
\hline Disagree & $1.54(0.88-2.7 I)$ & 0.133 \\
\hline Strongly disagree & $\mathrm{I} .14(0.54-2.4 \mathrm{I})$ & 0.722 \\
\hline \multicolumn{3}{|c|}{ Frequent mental distress } \\
\hline Less than 15 days & Reference & \\
\hline 15 days or more & $1.56(1.01-2.40)$ & 0.043 \\
\hline \multicolumn{3}{|c|}{ Hours spent watching TV daily } \\
\hline Less than 3 & Reference & \\
\hline 3 to 7 hours & $1.44(0.97-2.12)$ & 0.068 \\
\hline 8 or more & $2.34(1.23-4.46)$ & 0.009 \\
\hline \multicolumn{3}{|c|}{ Number of cigarettes per day } \\
\hline None & Reference & \\
\hline I to 20 & $0.56(0.35-0.89)$ & 0.014 \\
\hline More than 20 & $0.33(0.16-0.68)$ & 0.003 \\
\hline \multicolumn{3}{|l|}{ Drink days/month } \\
\hline None & Reference & \\
\hline I to 2 & $0.61(0.35-1.05)$ & 0.074 \\
\hline 3 or more & $0.49(0.25-0.96)$ & 0.037 \\
\hline \multicolumn{3}{|c|}{ 5+ Drinks/day per month } \\
\hline None & Reference & \\
\hline 1 to 2 & $1.13(0.52-2.46)$ & 0.764 \\
\hline 3 or more & $0.91(0.33-2.54)$ & 0.856 \\
\hline
\end{tabular}

*Adjusted for age, places to walk, worried about having enough food, days with impaired activities of daily living.

drinks per occasion. Vadstrup et al found the smallest waist circumference in persons who consumed 1-7 drinks per week.

In another Danish population-based study, Tolstrup et al studied both frequency of drinking and total alcohol intake [11]. They found obesity to be positively correlated with total drinks consumed but inversely correlated with frequency of drinking. Obesity was measured by waist circumference and hip circumference.

Finally, we note that Breslow and Smothers found a positive and linear relationship between BMI and quantity of alcohol, while drinking frequency was positively related to BMI [12]. The lowest BMI was found among persons who drank small quantities frequently. This study was limited to persons who never smoked, so the results may not be generalizable.

Our study differs from previous research in that it uses a sample drawn from a primary care population that is largely low-income. We employed BMI to measure obesity and we measured alcohol use with drinking frequency as well as intensity. Our measure of intensity (binge episodes) was answered too infrequently to allow for firm conclusions. With this design, we found that persons who drink more often were less likely to be obese. This finding corroborates the results reported by Breslow and Smothers. Since our study appears to be the first to focus on drinking frequency in a low-income primary care population, we think the results are useful to investigators who study the epidemiology of obesity.

Drinking frequency is inversely related to obesity in this sample of primary care patients who visited community medicine clinics. While it is unlikely that alcohol consumption has a direct beneficial effect on obesity, we suspect that a report of no alcohol consumption may be a proxy for some other, unknown variable that increases risk of obesity. One hypothesis is that persons who do not consume any alcohol may be following a religious prohibition that is associated with other behaviors that relate to obesity, such as group dining involving high-calorie meals. Another possible explanation is that a subgroup of 
persons who refrain from all alcohol but have frequent mental distress may be using food as a method for coping with stress.

Our finding about the relationship between drinking and lower risk of obesity clearly should be replicated in other studies before attributing it to any theory or generalizing it to other populations. Nevertheless, we note that earlier studies have reported that non-drinkers are at increased risk of obesity and the National Institute on Alcohol Abuse and Alcoholism (NIAAA) has found some benefits from moderate use of alcohol $[8,13,14,17-19]$. The NIAAA reported that the relationship between moderate alcohol consumption and weight gain, BMI, or obesity remains inconclusive. At the same time, there is some protective effect of moderate alcohol consumption on two major sequelae of obesity, i.e., metabolic syndrome and diabetes. And, of course, numerous studies have consistently found that coronary heart disease deaths are less likely for persons who consume moderate amounts of alcohol [17].

Our findings should not lead researchers or clinicians to conclude that high levels of alcohol consumption are healthy. In addition to the risk of alcoholism, persons who consume large amounts of alcohol are at increased risk for depressive symptoms. Since many of the subjects in our sample already have frequent mental distress, promoting moderate use of alcohol in this population would represent a misguided effort to combat obesity with adverse health ramifications analogous to recommending cigarette smoking as a weight-loss strategy.

Our study confirmed the known relationship between poor mental health and obesity. In 2001, the Behavioral Risk Factor Surveillance System (BRFSS) survey found that $10 \%$ of adults reported frequent mental distress (poor mental health $\geq 15$ days per month). Persons reporting frequent mental distress (FMD) were more likely to have adverse, but modifiable, health behaviors including smoking, drinking, physical inactivity, and obesity [19]. In a study examining BRFSS data aggregated across several years, $12.3 \%$ of women reported frequent mental distress and this group was more likely to consume cigarettes and alcohol [20]. Hence, persons with frequent mental distress are more likely to have physical problems that require treatment in primary care settings and engage in behaviors that make treatment more difficult. Identifying and treating the underlying causes of mental distress is important from an economic, medical, and psychological perspective [21-25].

In our study, persons with obesity were more likely to report frequent mental distress than persons who were not obese. "Frequent mental distress" is not diagnostic of any particular psychiatric illness, such as depression. Nevertheless, the increased self report of mental distress among patients with obesity suggests that psychopathology, potentially treatable, may be unrecognized in a group with several identifiable risk factors for depression.

In July 2003, the President's New Freedom Commission published recommendations calling for enhanced efforts to screen for mental disorders in primary care settings [26]. Depression screening in primary care settings has also been recommended by the US Preventive Task Force (USPTF) [27]. Obese patients represent a readily identifiable subgroup of patients that can clearly benefit from the use of office-based screening tools that are brief, inexpensive, and easy to administer. Despite the availability of a number of instruments available to screen for mental disorders in primary care settings, such screening often does not occur [28-30]. Although the reasons why screening has not been widely implemented are unclear, they include time constraints, lack of reimbursement, stigma (on the part of both the patient and the physician), and financial barriers to effective treatments (e.g., psychotherapy and antidepressant agents).

Finally, we note that health confidence, believing that one can control one's own health, appears to have a protective effect against obesity. Earlier research has shown that health confidence, sometimes called medical skepticism, is related to better self-rated health [31].

There are several limitations to this study. The use of selfreported data for height and weight may result in underestimation of true BMI. Additionally, the study population was intentionally chosen to over sample high-risk populations and may not be representative of the general community population. Epidemiological studies have demonstrated an association between physical and psychiatric disorders. Using a convenience sample of ambulatory care patients and their families may over represent the portion of persons with poor mental health. Lastly, this survey was taken from a rather homogeneous group that was relatively young. Only $13 \%$ of persons in this study were over 65 years old. The results of this study may not be applicable to all groups, especially geriatric patients.

\section{Conclusion}

Our findings demonstrated an association between obesity and frequency of alcohol consumption. This result is reminiscent of the discovery that moderate alcohol consumption was related to reduced risk of heart disease [17]. An accumulation of evidence on this point led some physicians to recommend consumption of one or two drinks a day to their patients. If other researchers find occasional 
drinking is related to reduced risk of obesity, a similar change in medical advice could occur.

The mechanism by which alcohol use might reduce obesity is not immediately clear. Some investigators have observed that consumption of sugars is greater among non-drinkers [32]. It is possible that alcohol is an appetite suppressant for regular drinkers who do not binge.

While the association between frequent mental distress and obesity is not new or surprising, recognition of that relationship may provide an easy, effective, and important screening mechanism to detect depression in primary care settings. We believe that obesity, particularly obesity in women, may identify a high risk group that can be targeted for depression screening in primary care settings. Replication of these results by other investigators is important. In particular, establishing a direct association between frequent mental distress and depression among obese women will be important in improving the health care in this group of patients.

Obesity seems to be a phenomenon of middle age. This suggests a cohort effect, probably related to community changes in energy balance in the past few decades (e.g. increasing eating quantity and calorie density, and decreasing physical activity. We also note that obesity in this sample seems to be associated with a constellation of personal characteristics: non-smoking, TV watching, mentally distressed, and alcohol abstaining. While it is tempting to try to "explain" each of these characteristics individually (e.g. smoking is known to reduce body weight), it might be more productive to look at them as a personality pattern. For example, if this pattern were interpreted as describing passive people with little self-efficacy, then it might be more effective to try changing their environments than their volitional behavior. Research projects are needed that sort out causal mechanisms and test 'health protection' approaches to weight control: i.e., experimental interventions targeted at changing the environments of the middle-aged person who may be unable to change her or his own behavior.

\section{Competing interests}

The author(s) declare that they have no competing interests.

\section{Authors' contributions}

JR planned the study, organized the survey and wrote the introduction, discussion and conclusions. BR wrote sections relating to mental health and AW wrote sections relating to family practice. AD analyzed the data and wrote the first draft of the methods and results.

\section{References}

I. Finkelstein EA, Fiebeldorn IC, Wang G: State-level estimates of annual medical expenditures attributable to obesity. Obesity Research 2004, I 2: 18-24.

2. Ford ES, Moriarty DG, Zack MM, Mokdad AH, Chapman DP: SelfReported Body Mass Index and Health-Related Quality of Life: Findings from the Behavioral Risk Factor Surveillance System. Obesity Research 200I, 9:2I-3I.

3. Basset MT, Perl S: Obesity: The Public Health Challenge for Our Time. Am J Public Health 2004, 94: I477.

4. Must A, Spadano J, Coakley EH, Field AE, Colditz G, Dietz WH: The disease burden associated with overweight and obesity. JAMA 1999, 282:1523-1529.

5. Tavani A, Negri E, La Vecchia C: Determinants of body mass index: a study from northern Italy. Int J Obes Relat Metab Disord 1994, 1 8:497-502.

6. Lopez R: Urban Sprawl and Risk for Being Overweight or Obese. Am J Public Health 2004, 94: I574-I579.

7. Rohrer JE, Rohland BM: Psychosocial risk factors for obesity in a family planning clinic. BMC Fam Pract 2004, 5:20.

8. Kaplan MS, Huguet N, Newsom JT, McFarland BH, Lindsay J: Prevalence and Correlates of Overweight and Obesity Among Older Adults: Findings From the Canadian National Population Health Survey. J Gerontol A Biol Sci Med Sci 2003, 58:1018-1030.

9. Haas JS, Lee LB, Kaplan CP, Sonneborn D, Phillips KA, Liang SY: The Association of Race, Socioeconomic Status and Health Insurance Status With the Prevalence of Overweight Among Children and Adolescents. Am J Public Health 2003, 93:2105-2II0.

10. Vadstrup ES, Petersen L, Sorensen TIA, Gronbaek M: Waist circumference in relation to history of amount and type of alcohol: results from the Copenhagen City Heart Study. Int J Obes Relat Metab Disord 2003, 27:238-346.

II. Tolstrup JS, Heitmann BL, Tjonneland AM, Overvad OK, Sorensen TIA, Gronbaek MN: The relation between drinking pattern and body mass index and waist and hip circumference. Int J Obes Relat Metab Disord 2005, 29:490-497.

12. Breslow RA, Smothers BA: Drinking patterns and body mass index in never smokers. National Health Interview Survey, | 997-200 I . Am J Epidemiol 2005, I6 1:368-376.

13. Smothers B, Bertolucci D: Alcohol consumption and health-promoting behaviors in a U.S. household sample: leisure-time physical activity. J Stud Alcohol 2001, 62:467-476.

14. Fine LJ, Philogene S, Gramling R, Coups EJ, Sinha S: Prevalence of Multiple Chronic Disease Risk Factors; 200 I National Health Interview Survey. Am J Prev Med 2004, 27(2S): I8-24.

I5. Okosun IS, Seale JP, Daniel JB, Eriksen MP: Poor health is associated with episodic heavy alcohol use: evidence from a National Survey. Pubic Health 2005, I I 9:509-5 I7.

16. Paschall MJ, Freisthler B, Lipton RI: Moderate alcohol use and depression in young adults: findings from a national longitudinal study. Am J Public Health 2005, 95:453-457.

17. National Institute on Alcohol Abuse and Alcoholism: State of the Science Report on the Effects of Moderate Drinking. National Institutes of Health, Department of Health and Human Services . December 19, 2003

18. Flechner-Mors M, Biesalski HK, Jenkinson CP, Adler G, Ditschuneit $\mathrm{HH}$ : Effects of moderate consumption of white wine on weight loss in overweight and obese subjects. Int J Obesity 2004, 28: |420-1426.

19. Strine TW, Balluz L, Chapman DP, Morarity DG, Owens M, Mokdad $\mathrm{AH}$ : Risk Behaviors and Healthcare Coverage Among Adults by Frequent Mental Distress Status, 200 I. Am J Prev Med 2004, 26:213-216.

20. Ahluwalia IB, Mack KA, Mokdad A: Mental and physical distress and high-risk behaviors among reproductive-age women. Obstetrics Gynecology 2004, I 04:477-483.

21. Simon GE, Fleck M, Lucas R, Bushnell DM: Prevalence and predictors of depression treatment in an international primary care study. Am J Psychiatry 2004, I 61 : 1626-34.

22. Wells K: Quality of Care for Primary Care Patients With Depression in Managed Care. Arch Fam Med 1999, 8:529-536.

23. Thompson D, Hylan T, McMullen W, Romeis M, Buesching D, Oster G: Predictors of a Medical-Offset Among Patients Receiving Antidepressant Therapy. Am J Psychiatry 1998, I 55:824-827. 
24. Lyness JM, King DA, Conwell Y, Duberstein PR, et al.: Self-Rated Health, Depression, and One-Year Health Outcomes in Older Primary Care Patients. Am J Geriatr Psychiatry 2004, | 2:110-1/3.

25. Rohrer JE: Medical care usage and self-rated mental health. BMC Public Health 2004, 4:3.

26. U.S. Department of Health and Human Services: Mental Health: A Report of the Surgeon General. Rockville, MD: U.S. Department of Health and Human Services, Substance Abuse and Mental Health Services Administration, Center For Mental Health Services, National Institutes of Health, National Institute of Mental Health 1999.

27. U.S Preventive Services Task Force: Guide to Clinical Preventive Services. 2nd edition. Washington DC: Office of Disease Prevention and Health Promotion; 1996.

28. Henkel V, Mergl R, Coyne JC, Kohnen R, Moller HJ, Hegerl U: Screening for depression in primary care: will one or two items suffice? Eur Arch Psychiatry Clin Neurosci 2004, 254:21 5-23.

29. McAlpine DD, Wilson AR: Screening for depression in primary care: what do we still need to know? Depress Anxiety 2004, 19:137-45.

30. Jarjoura D, Polen A, Baum E, Kropp D, Hetrick S, Rutecki G: Effectiveness of screening and treatment for depression in ambulatory indigent patients. J Gen Intern Med 2004, 19:78-84.

31. Rohrer JE, Borders TF: Healthy Skepticism. Prev Med 2004, 39:1234-I237.

32. Colditz GA, Giovannucci E, Rimm EB, Stampfer MJ, Rosner B, Speizer $\mathrm{FE}$, Gordis E, Willett WC: Alcohol intake in relation to diet and obesity in women and men. Am J Clin Nutr 199I, 54:49-55.

\section{Pre-publication history}

The pre-publication history for this paper can be accessed here:

http://www.biomedcentral.com/1471-2296/6/17/prepub

\section{Publish with Biomed Central and every scientist can read your work free of charge}

"BioMed Central will be the most significant development for disseminating the results of biomedical research in our lifetime. "

Sir Paul Nurse, Cancer Research UK

Your research papers will be:

- available free of charge to the entire biomedical community

- peer reviewed and published immediately upon acceptance

- cited in PubMed and archived on PubMed Central

- yours - you keep the copyright

Submit your manuscript here:

http://www.biomedcentral.com/info/publishing_adv.asp 